\title{
Improved Agrobacterium Tumefaciens-Mediated Transformation of Cucumber via Modified use of Antibiotics and Acetosyringone
}

\section{Li'ang Chai}

Zhejiang $A$ and $F$ University

Changxia Du ( $\sim$ changxiadu@zafu.edu.cn )

Zhejiang A and F University https://orcid.org/0000-0002-0366-2224

Huaifu Fan

Zhejiang $A$ and $F$ University

Chen Liu

Zhejiang $A$ and $F$ University

Yuyang Si

Zhejiang A and F University

\section{Research}

Keywords: Cucumber, Agrobacterium, Kanamycin, Bacteriostatic antibiotics, Acetosyringone, Genetic transformation

Posted Date: November 12th, 2020

DOI: https://doi.org/10.21203/rs.3.rs-104095/v1

License: (c) (i) This work is licensed under a Creative Commons Attribution 4.0 International License. Read Full License 


\section{Improved Agrobacterium tumefaciens-mediated}

\section{2 transformation of cucumber via modified use of antibiotics}

\section{3 and acetosyringone}

$4 \quad$ Li'ang Chai ${ }^{1}$, Changxia $\mathrm{Du}^{1,2}$, Huaifu Fan², Chen Liu, Yuyang Si

Zhejiang Provincial Key Laboratory of Agricultural Product Quality Improvement Technology, College of Agriculture and Food

Science, Zhejiang A\&F University, Hangzhou 311300, Zhejiang, P. R. China.

Li’ang Chai: LyonChai@Outlook.com

Changxia Du: changxiadu@zafu.edu.cn

Huaifu Fan: wwghff@126.com

Chen Liu: 903141747@qq.com

11 Yuyang Si: thisyy@Outlook.com

12 1: Co-first authors; ${ }^{2}$ : Corresponding author

\section{Abstract}

Background: Cucumber (Cucumis sativus) is one of the most important vegetable crops

in the world. As conventional breeding of cucumber is very challenging, genetic engineering is an alternative option to introduce important traits such as enhanced stress resistance and nutritional value. However, the efficiency of the transformation system depends on genotypes, transformation conditions, selection agents, etc. This study aims to speed up the process of Agrobacterium-mediated transformation of cucumber.

21 'Xintaimici', a very popular and typical north China-type cucumber variety, was transformed with Agrobacterium GV3101. The strain carried the pCAMBIA2300s plasmid, a double vector with the marker gene neomycin phosphotransferase II (npt II).

Results: The research results indicated that cefotaxime sodium was suitable for inhibiting 
Agrobacterium in the screening and bud elongation stages. Timentin was best used during the rooting stage. Furthermore, $25 \mathrm{mg} / \mathrm{L}$ kanamycin was used in the early stage of screening and increased to $50 \mathrm{mg} / \mathrm{L}$ for further screening. At the bud elongation and rooting stages, 75 and $100 \mathrm{mg} / \mathrm{L}$ kanamycin was used, respectively, to improve the screening efficiency. To obtain the highest regeneration frequency of resistant buds, 50, 150, and 100 $\mu \mathrm{M}$ acetosyringone was added in the pre-culture medium, infection solution, and co-culture medium, respectively. To confirm the presence of the transgenes, DNA from npt II transgenic cucumber plants was analysed by polymerase chain reaction after transplanting resistant regenerated plants.

Conclusions: We finally achieved an $8.1 \%$ conversion, which is among the highest values reported to date using the cucumber 'Xintaimici'. Thus, an effective protocol for Agrobacterium tumefaciens-mediated genetic transformation of cucumber was optimized.

Keywords: Cucumber, Agrobacterium, Kanamycin, Bacteriostatic antibiotics, Acetosyringone, Genetic transformation

\section{Background}

Cucumber (Cucumis sativus) is one of the most important vegetable crops widely grown in the world. Studies on the gene function and genetic breeding of cucumber have been conducted worldwide[1,2]. Abnormal expression of genes in transgenic cucumber plants can help us to engineer and select more robust crop species, such as resistance to biotic and abiotic stress, improved fruit 
quality[3], growth and development[4, 5]. Since the advent of cucumber tissue culture and genetic transformation technology[6,7], researchers have made great achievements in the transformation of genes through the improvement and optimization of transformation methods. At present, the Agrobacterium tumefaciens-mediated transformation system of cucumber is still one of the most mature and popular genetic transformation methods[8]. However, the genetic transformation efficiency of cucumber remains low. The key factors affecting the infection efficiency of Agrobacterium include the type of explant[9], Agrobacterium species[10], exogenous hormone[11, 12], selection agent[13], Agrobacterium inhibitors[14] and phenols[15]. In addition, the cutting method for explants[16] and the mode of infection, such as vacuum infiltration treatment $[13,15]$, also have an impact on the transformation of cucumber to varying degrees.

In the selective culture stage of cucumber genetic transformation, selection antibiotics and antimicrobial antibiotics are often used together[17]. Kanamycin, hygromycin and glyphosate commonly are used for selection markers[13]. It is generally believed that the resistance of cucumber explants to selection antibiotics is closely related to their genotype and culture stages. Instead, antibiotics that have little effect on explants and a certain inhibition effect on Agrobacterium are often selected and used[17, 18], such as cefotaxime sodium, carbenicillin, and timentin[15]. However, they are often used at a high concentration, which also has a certain impact on the regeneration and growth of explants[19]. Many studies found that phenolics had a significant effect on the regeneration frequency of resistant buds when added to the pre-culture, infection and coculture stages of genetic transformation[15, 20]. It is widely recognized that phenolics, such as 
acetosyringone, can activate the vir gene of Agrobacterium and promote the introduction of foreign genes into the plant genome, and then the efficiency of genetic transformation is improved[21]. However, acetosyringone is often dissolved in toxic organic solvents or has toxic effects at high concentrations and interacts with infection modes and other transformation conditions[22]. Therefore, the specific addition stages and concentrations of acetosyringone were different in existing reports[1].

Nonconformity between the infection site of Agrobacterium and the regeneration site of explants is the most important reason for the low efficiency of the genetic transformation of cucumber. Additionally, the inconsistent sites are affected by various conditions and factors[1,23]. In addition, the selection and the concentration of antibiotics are the main factors affecting the regeneration of positive buds[14]. However, these parameters were different in various reports in the literature and lack sufficient detail in existing studies. All of these reasons lead to browning, Agrobacterium pollution, vitrification shoots, low efficiency of genetic transformation[24], gene expression and genetic instability, which still perplex researchers. To improve the efficiency of genetic transformation, the effects of different concentrations of kanamycin on the regeneration of cotyledonary nodes applied in different transformation periods were analysed in the present study.

Meanwhile, the inhibitory effects of three different antibiotics on Agrobacterium and the effects on regenerated buds were evaluated, and the effects of acetosyringone on the regeneration frequency of resistant buds in different stages of cucumber genetic transformation were investigated. This study hopes to provide a reference for future research on transgenic cucumber. 


\section{Results}

\section{Effects of kanamycin on the regeneration frequency and browning of explants}

The untransformed explants were placed in media with different kanamycin concentrations for $28 \mathrm{~d}$ (Fig. 1-a). The regeneration frequency of buds and the browning level showed opposite trends with the increase in the kanamycin concentration. The regeneration frequency of $0 \mathrm{mg} / \mathrm{L}$ treatment was $90.0 \%$ and was significantly higher than that of any other treatments. Prominent differences were observed between 25,75 , and $100 \mathrm{mg} / \mathrm{L}$ treatments. However, the regeneration frequencies of 50,75 , and $100 \mathrm{mg} / \mathrm{L}$ treatments were not notably different. Browning began to appear with $50 \mathrm{mg} / \mathrm{L}$ treatment and reached the peak with $100 \mathrm{mg} / \mathrm{L}$ treatment (90.0\%). Except for $100 \mathrm{mg} / \mathrm{L}$ treatment, there was no obvious difference among the other treatments (Fig. 1-b).

\section{Effects of bacteriostatic antibiotics on Agrobacterium and explants}

The explants were cultured in selective media containing $300 \mathrm{mg} / \mathrm{L}$ cefotaxime sodium, carbenicillin, or timentin for $28 \mathrm{~d}$ (Fig. 2-a). The experiment identified that the three antibiotics at $300 \mathrm{mg} / \mathrm{L}$ could inhibit the growth of Agrobacterium on the explants. Cefotaxime sodium treatment had the highest resistant bud frequency (76.7\%) and shared the same level of difference with timentin treatment. The lowest resistant bud frequency (43.3\%) came from carbenicillin treatment and showed no significant difference with timentin treatment (Fig. 2-b). Part c of Fig. 2 shows the growth of Agrobacterium on different types of antibiotics. When the culture time reached $96 \mathrm{~h}$, the highest diameter of the inhibition zone was observed with timentin treatment $(6.4 \mathrm{~cm})$. In contrast, carbenicillin treatment was the lowest $(5.6 \mathrm{~cm})$. Significant differences were seen in all treatments. 

inhibition zone $(5.8 \mathrm{~cm})$ in response to timentin treatment was observed. Furthermore, the result was similar to the timentin and cefotaxime sodium treatments. However, the diameter of the inhibition zone with carbenicillin treatment decreased significantly and reached the lowest level (4.4 cm) over time (Fig. 2-d). In another experiment, uninfected explants were cultured with different concentrations of cefotaxime for 28 d (Fig. 2-e). With the increase in cefotaxime sodium concentration, the number of regenerated buds in each explant decreased from 7.1 to 2.7 , which was a reduction of almost 4 times. Compared with $0 \mathrm{mg} / \mathrm{L}$ treatment, the $100 \mathrm{mg} / \mathrm{L}$ treatment did not significantly alter the number of regeneration buds. The number of regeneration buds with the 0 and $100 \mathrm{mg} / \mathrm{L}$ treatments was significantly higher than that with any other treatments. There was no significant difference among the 200, 300 and $400 \mathrm{mg} / \mathrm{L}$ treatments (Fig. 2-f).

\section{Effects of acetosyringone on the regeneration of resistant buds}

$28 \mathrm{~d}$ and are shown as follows.

In the test with added acetosyringone in the pre-cultivation stage, the frequency of resistant buds increased initially and then decreased with an increase in the acetosyringone concentration.

123 Treatment at $50 \mu \mathrm{M}$ had the highest frequency of resistant buds (53.3\%), which was significantly higher than that observed with the 100,200 , and $400 \mu \mathrm{M}$ treatments. However, acetosyringone 
greater than or equal to $100 \mu \mathrm{M}$ showed severe inhibition of the frequency of resistant buds. There was no notable difference between the 0 and $50 \mu \mathrm{M}$ treatments (Fig. 3-e). As shown in Fig. 3-f, the final frequency of resistant buds increased first and then decreased with the increase in acetosyringone concentration in the Agrobacterium inoculation process. The regeneration frequency of resistant buds reached the peak (53.3\%) under $150 \mu \mathrm{M}$ treatment, which was significantly lower than that under $200 \mu \mathrm{M}$ treatment (20.0\%). Other than $150 \mu \mathrm{M}$ treatment, no significant difference was found between any other treatments. From Fig. 3-g, we know that the frequency of resistant buds increased first and then decreased with the increase in acetosyringone concentration in the cocultivation stage. Treatment at $100 \mu \mathrm{M}$ had the highest regeneration frequency of resistant buds (80.0\%), which differed from the 50 and $200 \mu \mathrm{M}$ treatments to the same degree and was significantly higher than that with the 0 and $400 \mu \mathrm{M}$ treatments. The lowest regeneration frequency of resistant buds was with the 0 and $400 \mu \mathrm{M}$ treatments (33.3\%), which showed no obvious difference compared with the 50 and $200 \mu \mathrm{M}$ treatments. The explants grew in a screening medium with additional of resistant buds while in the early stages of transformation but not after screening (Fig. 3). acetosyringone, and the results are shown in Fig. 3-h. By increasing the concentration of acetosyringone from 0 to $200 \mu \mathrm{M}$, the frequency of resistant buds decreased from $53.3 \%$ to $23.3 \%$. The frequencies of resistant buds under the 0,50 , and $100 \mu \mathrm{M}$ treatments showed the same degree of difference, and the 50,100,150, and $200 \mu \mathrm{M}$ treatments shared another difference level. Taken together, these results suggested that extra acetosyringone could increase the regeneration frequency

\section{Polymerase chain reaction (PCR) analysis}


primers of the Agrobacterium genome were used to eliminate the contamination of plants from and 18 (Fig. 4-b). DNA of wild-type plants and negative controls was not amplified (Fig. 4).

\section{Discussion}

system for cucumber. We evaluated the optimal dosage of kanamycin and various antimicrobial antibiotics by observing the growth of explants and Agrobacterium in different concentrations. The amount of added acetosyringone was changed when applied to different culture stages. Then, the optimized regeneration protocol was adapted for transformation of cucumber.

\section{Effects of kanamycin on explants}


concentration of kanamycin could be increased to 75 and $100 \mathrm{mg} / \mathrm{L}$ to prevent the emergence of false-positive plants[28] at the bud elongation and rooting culture stages. The dynamic concentration of kanamycin $(50-100 \mathrm{mg} / \mathrm{L})$ agreed with relevant reports $[29,30]$.

\title{
Effects of bacteriostatic antibiotics on Agrobacterium and explants
}

\author{
Different strains of Agrobacterium had different sensitivities to antibiotics[31]. The specific
} effect of antimicrobial antibiotics was not reported in cucumber transformation. Therefore, it is very important to select antibiotics that can effectively inhibit the pollution of Agrobacterium GV3101 and have little effect on cucumber regeneration buds simultaneously. There were significant differences in the effects of three commonly used antimicrobial antibiotics (cefotaxime sodium, carbenicillin, and timentin) on the explants and Agrobacterium. These data demonstrated that the highest regeneration frequency of resistant buds could be obtained by using cefotaxime sodium (Fig. 2-a and b). This result might be due to its chemical structure, which is related to auxin and could interact with other substrates in the culture medium[32]. Timentin had the best antibacterial effect and the longest duration relative to the others (Fig. 2-c and d) due to its high resistance to $\beta$ lactamases produced by bacteria[33], but it was not as cheap and common as cefotaxime sodium for practical use. Additionally, we found that the medium containing cefotaxime sodium (Fig. 5-II) would turn yellow gradually within 2 weeks in the bud elongation culture stage, while this was not observed in the medium with timentin (Fig. 5-I). It was reported that the yellowed medium, which contained harmful substances, was caused by the accumulation of o-quinones through enzymatic browning[34]. On the other hand, the toxic effect of cefotaxime sodium on shoot rooting had been 
reported[17]. In this sense, cefotaxime sodium was more suitable for cucumber genetic transformation and could be added to the medium in the selective and bud elongation culture stages, while timentin could be added to the rooting culture stage because of its long lasting effect[35]. Additionally, carbenicillin was unsuitable for the genetic transformation of cucumber 'Xintaimici'. The effect of cefotaxime sodium on the explants further indicated that the $100 \mathrm{mg} / \mathrm{L}$ concentration of cefotaxime sodium had little effect on explants, while $500 \mathrm{mg} / \mathrm{L}$ showed significant inhibition

(Fig. 2-e and f). The suitable concentration of cefotaxime sodium was $200-400 \mathrm{mg} / \mathrm{L}$, which could be adjusted according to the extent of pollution from Agrobacterium.

\section{Effects of acetosyringone on the regeneration of resistant buds}

Yadav et al. indicated that twelve low-molecular-weight phenolic compounds and salicylic acid were the main substances secreted after explants of chickpea (Cicer arietinum L.) were injured, and polyphenol oxidase was activated to oxidize phenols[34]. These processes led to the decrease in phenol and the increase in o-quinones gradually with time, which was one of the factors that resulted in the difficulty of T-DNA transport. Additionally, secretions such as salicylic acid and gallic acid inhibited the growth and transformation of Agrobacterium. In many studies, the transformation efficiency of cucumber was improved by adding an additional phenol, such as acetosyringone[20, 27]. Improved efficiency could also be achieved by inhibiting the oxidation of phenols, such as via the addition of antioxidants including $\alpha$-caprylic acid, L-cystine, dithiothreitol, and $\mathrm{Na}_{2} \mathrm{~S}_{2} \mathrm{O}_{3}$ [34]. In this study, adding different concentrations of acetosyringone in four key steps of genetic transformation showed that the concentration of acetosyringone had a significant effect on the 
regeneration of resistant buds. The analysed results showed that the addition of acetosyringone had a significant effect on the regeneration of resistant buds in different stages (Fig. 3). In the precultivation stage, only $50 \mu \mathrm{M}$ acetosyringone was needed to improve the regeneration frequency of resistant buds. The regeneration frequency of resistant buds was lower than the control level $(0 \mu \mathrm{M}$ treatment) with an acetosyringone concentration that was too high. The best concentration of acetosyringone in the infection liquid of Agrobacterium was $150 \mathrm{mg} / \mathrm{L}$. Furthermore, the high concentration made the regeneration frequency of resistant buds drop sharply. Similarly, the optimum concentration of acetosyringone in the co-culture medium was $100 \mathrm{mg} / \mathrm{L}$, and the highest regeneration frequency of resistant buds was $80.0 \%$. In the stage of selective culture, the extra acetosyringone did not help increase the regeneration frequency of resistant buds. In contrast, the presence of acetosyringone decreased the differentiation resistance of explants. Through these experiments, we successfully determined the content of acetosyringone in the process of cucumber

217 genetic transformation as a basis for improving the transgenic efficiency of the cucumber

\section{Conclusions} mediated genetic transformation[36]. New technologies such as CRISPR/Cas9[1, 37] and selection markers with no antibiotic[38] were also applied to the genetic transformation of cucumber. The Agrobacterium tumefaciens-mediated transformation system of cucumber is still one of the most 
the most difficult species to transform, although it has been carried out for 39 years[7]. The highest transformation efficiency of cucumber was $26 \%[2]$, while the lowest was only $0.1 \%$, and most reports are between $1 \%$ and $10 \%[2]$. Moreover, there have been few reports about the transformation of cucumber 'Xintaimici' [39].

The transformation method reported here is a modification and improvement scheme building on previous reports in cucumber. The complete transformation method was used in the study, and the main steps are shown in Fig. 5. We increased the infection depth through the vacuum system, and we set a gradient concentration of kanamycin to prevent damage to tender plants and the emergence of false-positive and chimeric plants. We used three antimicrobial antibiotics in different stages and compared their effects on the growth of Agrobacterium GV3101 and explants. By changing the usage of acetosyringone in the important genetic transformation stages, we improved the regeneration frequency of resistant buds by increasing the content of phenolics. We successfully obtained transgenic plants from the cotyledonary nodes of cucumber 'Xintaimici' after 3 months of application of the improved genetic transformation system (Fig. 5). From 223 explants, 134 resistant buds were regenerated, and 42 rooting regenerated plants were obtained. At last, 18 plants were identified as positive. The positive rate was $42.8 \%$, and the transgenic efficiency was $8.1 \%$, which was improved compared with other reports[39]. This project was undertaken to improve the Agrobacterium-mediated transformation of cucumber with a similar genetic background as 'Xintaimici' and laid a foundation for other gene transformation work. 


\section{Materials and Methods}

245

246

247

\section{Plant materials and media}

The seeds of cucumber 'Xintaimici' (a north China-type cucumber variety) were soaked for 2$3 \mathrm{~h}$ in water, and the seed coats were peeled. The unclad seeds were dipped in $75 \%$ ethanol for 1 min and $15 \%$ sodium hypochlorite for $15 \mathrm{~min}$ and then were rinsed 4 times in sterile distilled water. The sterilized seeds were germinated in the dark at $28^{\circ} \mathrm{C}$ for $48 \mathrm{~h}$ and light for $24 \mathrm{~h}$ with medium-I (2.21 g/L M519 (PhytoTechnology, America) $+15 \mathrm{~g} / \mathrm{L}$ sucrose $+2.5 \mathrm{~g} / \mathrm{L}$ phytagel, $\mathrm{pH}=6.8)$. Cotyledonary nodes were first cut in half, $2 \mathrm{~mm}$ hypocotyls were retained, and the distal 2/3 parts and growth point were removed. Cotyledonary nodes were cultured in medium-II (4.43 g/L M519 $+30 \mathrm{~g} / \mathrm{L}$ sucrose $+2.5 \mathrm{~g} / \mathrm{L}$ phytagel $+0.5 \mathrm{mg} / \mathrm{L}$ 6-benzylaminopurine $+1.0 \mathrm{mg} / \mathrm{L}$ abscisic acid[40] $\left.+1.0 \mathrm{mg} / \mathrm{L} \mathrm{AgNO}_{3}, \mathrm{pH}=6.8\right)$ with varying concentrations $(0,50,100,150$, and $200 \mu \mathrm{M})$ of acetosyringone in the dark at $28^{\circ} \mathrm{C}$ for $24 \mathrm{~h}$.

\section{Agrobacterium strain and vector}

The Agrobacterium strain GV3101 was used for transformation. The binary vector was pCAMBIA2300s, including the neomycin phosphotransferase II ( $n p t$ II) selection marker, driven by the CaMV-35S promoter. The Agrobacterium was resuscitated in Luria-Bertani (LB)-I medium (5 $\mathrm{g} / \mathrm{L}$ yeast extract $+10 \mathrm{~g} / \mathrm{L}$ tryptone $+10 \mathrm{~g} / \mathrm{L} \mathrm{NaCl}+15 \mathrm{~g} / \mathrm{L}$ agar, $\mathrm{pH}=5.8)$ with $50 \mathrm{mg} / \mathrm{L}$ kanamycin and $25 \mathrm{mg} / \mathrm{L}$ rifampicin at $28^{\circ} \mathrm{C}$ until single colonies appeared. The Agrobacterium single colonies were added to $1 \mathrm{~mL}$ of LB II ( $5 \mathrm{~g} / \mathrm{L}$ yeast extract $+10 \mathrm{~g} / \mathrm{L}$ tryptone $+10 \mathrm{~g} / \mathrm{L} \mathrm{NaCl}, \mathrm{pH}=5.8)$ with 50 $\mathrm{mg} / \mathrm{L}$ kanamycin and $25 \mathrm{mg} / \mathrm{L}$ rifampicin at $28^{\circ} \mathrm{C}$ until turbid. Then, the Agrobacterium was cultured 
with $100 \mathrm{~mL}$ of LB II containing $50 \mathrm{mg} / \mathrm{L}$ kanamycin and $25 \mathrm{mg} / \mathrm{L}$ rifampicin at $28^{\circ} \mathrm{C}$ until an optical density at $600 \mathrm{~nm}\left(O D_{600}\right)$ of $0.6-0.8$ was achieved. The Agrobacterium culture was centrifuged and resuspended in medium-III (2.21 g/L M519 $+15 \mathrm{~g} / \mathrm{L}$ sucrose, $\mathrm{pH}=6.8)$, and the final concentration of the Agrobacterium (Measured by $O D_{600}$ ) was adjusted to $0.2-0.3$. Varying concentrations $(0,50,100,150$, and $200 \mu \mathrm{M})$ of acetosyringone were added to medium-III. Before inoculation, the resuspended Agrobacterium inoculum was shaken for the induction of vir genes at $28^{\circ} \mathrm{C}$ for $1 \mathrm{~h}$.

\title{
Effects of kanamycin and bacteriostatic antibiotics on Agrobacterium and explants
}

\author{
Explants that were not being exposed to Agrobacterium were placed on medium-II. Varying
} concentrations of kanamycin $(0,25,50,75$, and $100 \mathrm{mg} / \mathrm{L})$ and cefotaxime sodium $(0,100,200$, 300, 400, and $500 \mathrm{mg} / \mathrm{L}$ ) were added in medium-II. Petri dishes were placed in the tissue culture room at $28^{\circ} \mathrm{C}, 4000 \mathrm{Lx}, 16 \mathrm{~h} / \mathrm{d}$. The medium was changed every 2 weeks for $28 \mathrm{~d}$. A total of $100 \mu \mathrm{L}$ of the Agrobacterium $\left(O D_{600}=0.7\right)$ was added to LB-I medium. A piece of sterile filter paper $6 \mathrm{~mm}$ in diameter with $0.5 \mathrm{mg}$ of bacteriostatic antibiotics (cefotaxime sodium, carbenicillin, and timentin) was placed in the centre. Petri dishes were placed in $28^{\circ} \mathrm{C}$ bacterial incubators for $96 \mathrm{~h}$ and $30 \mathrm{~d}$.

Inoculation, co-cultivation, screening, and regeneration

$$
\text { Explants were immersed in Agrobacterium inoculum in sterile Erlenmeyer flasks with }
$$
breathable filter membranes. Erlenmeyer flasks were placed in a vacuum system at $0.094 \mathrm{MPa}$ for $5 \mathrm{~min}$. The vacuum was relieved slowly to prevent damage to explants caused by stress transients. 
$48 \mathrm{~h}[41,42]$. Varying concentrations $(0,50,100,200$, and $400 \mu \mathrm{M})$ of acetosyringone were added in medium-II. After co-cultivation, explants were washed 5 times with sterilized distilled water. Explants were blotted dry on sterile filter paper. Then, explants were transferred to medium-II. Kanamycin at $50 \mathrm{mg} / \mathrm{L}$, varying concentrations of acetosyringone $(0,50,100,200$, and $400 \mu \mathrm{M})$ and bacteriostatic antibiotics (cefotaxime sodium, carbenicillin, and timentin, $300 \mathrm{mg} / \mathrm{L}$ ) were added in medium-II. Petri dishes were placed in the tissue culture room at $28^{\circ} \mathrm{C}, 4000 \mathrm{Lx}, 16 \mathrm{~h} / \mathrm{d}$. The medium was changed every 2 weeks until 2-cm-high regenerating buds were grown.

Resistant regenerating buds were cut off and transferred to medium-IV (4.43 g/L M519 + 30 $\mathrm{g} / \mathrm{L}$ sucrose $+2.5 \mathrm{~g} / \mathrm{L}$ phytagel $+0.2 \mathrm{mg} / \mathrm{L}$ 6-benzylaminopurine $+1.0 \mathrm{mg} / \mathrm{L} \mathrm{AgNO}_{3}, \mathrm{pH}=6.8$ ) containing $75 \mathrm{mg} / \mathrm{L}$ kanamycin and $300 \mathrm{mg} / \mathrm{L}$ cefotaxime sodium or timentin to grow for 2 weeks. Then, the resistant regenerating buds were transferred to medium-V $(2.21 \mathrm{~g} / \mathrm{L} \mathrm{M} 519+15 \mathrm{~g} / \mathrm{L}$ sucrose $+2.5 \mathrm{~g} / \mathrm{L}$ phytagel $+1.0 \mathrm{mg} / \mathrm{L} \mathrm{AgNO}_{3}, \mathrm{pH}=6.8$ ) containing $100 \mathrm{mg} / \mathrm{L}$ kanamycin and 300 $\mathrm{mg} / \mathrm{L}$ timentin to induce rooting for 2 weeks. The regeneration plants with flourishing roots were transferred into the matrix ( $\left.V_{\text {Peat: }} V_{\text {Perlite }}=1: 1\right)$ and cultivated in an artificial climate chamber (Day: $28^{\circ} \mathrm{C}, 6000 \mathrm{Lx}, 16 \mathrm{~h}$; Night: $18^{\circ} \mathrm{C}, 8 \mathrm{~h}$; Relative humidity: $65 \%$ )[42]. Each regeneration cucumber was covered with cling film to maintain humidity for 1 week. Then, the cucumber plants were managed by normal water and fertilizer[44].

\section{DNA isolation and PCR analysis}

Cucumber 'Xintaimici' was genetically modified with the improved genetic transformation system. After obtaining regenerated plants, the ninth new leaf of the cucumber regeneration plants 
was removed, rapidly frozen with liquid nitrogen, and their total DNA was extracted by the CTAB method[45]. PCR was used to confirm the presence of the transgene in primary transformants. PCRs were carried out in a $20 \mu \mathrm{L}$ volume containing $2 \mu \mathrm{L}$ of $10 \times$ PCR Buffer, $200 \mu \mathrm{M}$ of each dNTP, 0.4 U Taq DNA polymerase, $100 \mathrm{ng}$ template DNA, and $1 \mu \mathrm{M}$ of each primer. The primer sequences were $n p t$ II Forward 5'-TCGGCTATGACTGGGCACAACAGA-3' and npt II Reverse 5'AAGAAGGCGATAGAAGGCGATGCCT-3', yielding an amplification product of $480 \mathrm{bp}$. Agrobacterium genome exclusion primers were $\operatorname{HrcA}$ Forward 5'CATCGTCGAAGGTTATCTCGATACG-3' and HrcA Reverse 5'TATAATCGACCATCGGTACGATACG-3'[15], yielding an amplification product of $800 \mathrm{bp}$. PCR amplification was performed as follows: $94^{\circ} \mathrm{C}$ for $3 \mathrm{~min} ; 35$ cycles of $94^{\circ} \mathrm{C}$ for $30 \mathrm{~s}, 58^{\circ} \mathrm{C}$ for $30 \mathrm{~s}$,

314 and $72^{\circ} \mathrm{C}$ for $1 \mathrm{~min}$; followed by a final extension of $72^{\circ} \mathrm{C}$ for $10 \mathrm{~min}$. PCR products were separated on a $1 \%$ agarose gel and visualized by ethidium bromide staining.

\section{References}

$317[1] \mathrm{Hu}$, B, et al. Engineering non-transgenic gynoecious cucumber using an improved

[2] Zhang, ZX, et al. A protocol for Agrobacterium-mediated transformation of cucumber transformation protocol and optimized CRISPR/Cas9 system. Mol Plant. 2017; 10(12): 1575- 
associated with organ size variation in cucumber. Plant J. 2018; 95(5): 834-847.

325

[4] Zhao, W, et al. CsTFL1b may regulate the flowering time and inflorescence architecture in cucumber (Cucumis sativus L.). Biochem Bioph Co. 2018; 499(2): 307-313.

[5] Liu, PP, et al. Expression vector construction of Rubisco activase gene $C s R C A$ and genetic transformation to cucumber. Acta Hortic Sin. 2012; 39(5): 869-878.

[6] Sato, M, Imanishi, S, Hiura, I. In vitro plantlet formation from hypocotyl and hypocotyl callus of Cucumis sativus L. Jpn J Breed. 1979; 29(1): 33-38.

[7] Wehner, TC, Locy, R. In vitro adventitious shoot and root formation of cultivars and lines of Cucumis sativus L. Hort Sci. 1981; 16(6): 759-760.

[8] Jiang, L, et al. Transcriptomic analysis reveals the roles of microtubule-related genes and transcription factors in fruit length regulation in cucumber (Cucumis sativus L.). Sci Rep. 2015; 5: 8031 .

[9] Wang, $\mathrm{Y}$, et al. Genetic analysis and identification of a candidate gene associated with in vitro regeneration ability of cucumber. Theor Appl Genet. 2018; 131(12): 2663-2675.

[10] Chetty, VJ, et al. Evaluation of four Agrobacterium tumefaciens strains for the genetic transformation of tomato (Solanum lycoper-sicum L.) cultivar Micro-Tom. Plant Cell Rep. 2013; 32(2): 239-247.

[11] Wang, W, et al. Cucumber ECERIFERUM1 (CsCER1), which influences the cuticle properties and drought tolerance of cucum-ber, plays a key role in VLC alkanes biosynthesis. Plant Mol 
Biol. 2015; 87(3): 219-233.

344 [12] Mohiuddin, AKM, et al. Influence of silver nitrate (ethylene inhibitor) on cucumber in vitro shoot. Plant Cell Tiss Org. 1997; 51: 75-78.

[13] Wang, SL, et al. Current status of genetic transformation technology developed in cucumber (Cucumis sativus L.). J Integr Agr. 2015; 8(12): 469-482.

[14] Kim, HA, et al. Development of transgenic cucumber expressing TPSP gene and morphological alterations. J Plant Bio. 2010; 37(1): 72-76.

[15] Nanasato, Y, et al. Improvement of Agrobacterium-mediated transformation of cucumber (Cucumis sativus L.) by combination of vacuum infiltration and co-cultivation on filter paper wicks. Plant Biotechnol Rep. 2013; 7(3): 267-276.

[16] Prem, AR, Rafael, PT. Improved cucumber transformation by a modified explant dissection and selection protocol. Hort Sci. 2005; 40: 431-435.

[17] Estopà, M, et al. Study of different antibiotic combinations for use in the elimination of Agrobacterium with kanamycin selection in carnation. Plant Cell Tiss Org. 2001; 65: 211-220.

[18] Ogawa, Y, Mii, M. Meropenem and moxalactam: Novel $\beta$-lactam antibiotics for efficient Agrobacterium-mediated transformation. Plant Sci. 2007; 172: 564-572.

[19] Holford, P, Newbury, HJ. The effects of antibiotics and their breakdown products on the in vitro growth of Antirrhinum majus. Plant Cell Rep. 1992; 11: 93-96.

[20] Kose, E, Koç, NK. Agrobacterium-mediated transformation of cucumber (Cucumis Sativus L.) 
and plant regeneration. Biotechnol Biotec Eq. 2014; 17(2): 56-62.

363

364

[21] Nazzaro, F, Fratianni, F, Coppola, R. Quorum sensing and phytochemicals. Int J Mol Sci. 2013; 14: $12607-12619$.

[22] Yang, H, et al. Establishment of genetic transformation system by Agrobacterium tumefaciens of cucumber. Southwest China J Agric Sci Rep. 2014; 27(4): 1656-1660.

[23] Bhattacharya, A, Sood, P, Citovsky, V. The roles of plant phenolics in defense and communication during Agrobacterium and Rhizobium infection. Mol Plant Pathol. 2010; 11: $705-719$.

[24] Sun, YD, et al. Establishment of a high-efficiency genetic transformation system of cucumber (Cucumis sativus) using Csexpansin 10 (CsEXP10) gene. Int J Agric Biol. 2017; 19(03): 545550.

[25] Gaba, V, Zelcer, A, Gal-On, A. Cucurbit biotechnology: the importance of virus resistance. In vitro Cell Dev-Pl. 2004; 40: 346-558.

[26] Vasudevan, A, et al. Agrobacterium-mediated transformation in cucumber (Cucumis sativus L.). Cucurbit Genetics Cooperative Report. 25: 14-16.

[27] Soryu, NT, Hiroyasu, K, Takahiko, HI. Transformation of cucumber (Cucumis sativus L.) plants using Agrobacterium tumefaciens and regeneration from hypocotyl explants. Plant Cell Rep. 1996; 15: 809-814.

[28] Paul, C, Dennis, E, McCabe. Prediction of germ-line transformation events in chimeric Ro 

290.

[29] Raharjo, SHT, et al. Transformation of pickling cucumber with chi-tinase-encoding genes using Agrobacterium tumefaciens. plant Cell Rep. 1996; 15: 591-596.

[30] Raharjo, SHT, Punja, ZK. Regeneration of plantlets from embryogenic suspension cultures of

[31] Gelvin, SB. Agrobacterium-mediated plant transformation: the biology behind the 'genejockeying' tool. Microbiol Mol Biol Rev. 2003; 67(1): 16-37.

[32] Ling, HQ, Kriseleit, D, Ganal, MW. Effect of ticarcillin/potassium clavulanate on callus growth and shoot regeneration in Agrobacterium-mediated transformation of tomato (Lycopersicon esculentum Mill.). Plant Cell Rep. 1998; 17: 843-847.

[33] Labia, R, Morand, A, Peduzii, J. Timentin and $\beta$-lactamases. J. Antimicrob. Chemother. 1986; 17(Suppl C): 17-26.

[34] Yadav, R, et al. Improvement in Agrobacterium-mediated transformation of chickpea (Cicer arietinum L.) by the inhibition of polyphenolics released during wounding of cotyledonary node explants. Protoplasma. 2015; 254(1): 253-269.

[35] Cheng, ZM, Schnurr, JA, Kapaun, JA. Timentin as an alternative antibiotic for suppression of Agrobacterium tumefaciens in genetic transformation. Plant Cell Rep. 1998; 17(8): 646-649. 
[36] Anjum, NA, et al. Transport phenomena of nanoparticles in plants and animals/humans. Environ Res. 2016; 151: 233-243.

[37] Chandrasekaran, J, et al. Development of broad virus resistance in non-transgenic cucumber using CRISPR/Cas9 technology. Mol Plant Pathol. 2016; 17(7): 1140-1153.

[38] He, ZQ, et al. Mannose selection system used for cucumber transformation. Plant Cell Rep. 2006; 25(9): 953-958.

[39] Wang, J, et al. Agrobacterium-mediated transformation of cucumber (Cucumis sativus L.) using a sense mitogen-activated protein kinase gene (CsNMAPK). Plant Cell Tiss Org. 2013; 113: 269-277.

[40] Tabei, $\mathrm{Y}$ et al. Transgenic cucumber plants harboring a rice chitinase gene exhibit enhanced resistance to gray mold (Botrytis cinerea). Plant Cell Rep. 1998, 17(3): 159-164.

[41] Bakshi, S, et al. Agrobacterium-mediated transformation of cowpea via sonication and vacuum infiltration. Plant Cell Rep. 2011; 30: 2281-2292.

[42] de Oliveira, MLP, et al. High-efficiency Agrobacterium-mediated transformation of citrus via sonication and vacuum infiltration. Plant Cell Rep. 2009; 28: 387-395.

[43] Selvaraj, N, et al. In vitro organogenesis and plant formation in cucumber. Biol Plantarum. 2006; 50(1): 123-126.

[44] Li, X, et al. A protocol for Agrobacterium-mediated transformation of cucumber (Cucumis sativus L.) from cotyledon explants. Plant Biotechnol J. 2017; 9(6): 405-416. 
[45] Li, HQ, et al. Genetic transformation of Torenia fournieri using the PMI/mannose selection system. Plant Cell Tiss Org. 2007; 90(1): 103-109.

\section{Ethics approval and consent to participate}

\section{Consent for publication}

Availability of data and materials

All data generated or analysed during this study are available in this published article.

Competing interests

\section{Funding} experiments. L. C. wrote the paper with input from all authors.

437 We are grateful for help from the Zhejiang Provincial Key Laboratory of Agricultural Product 


\section{Figures}

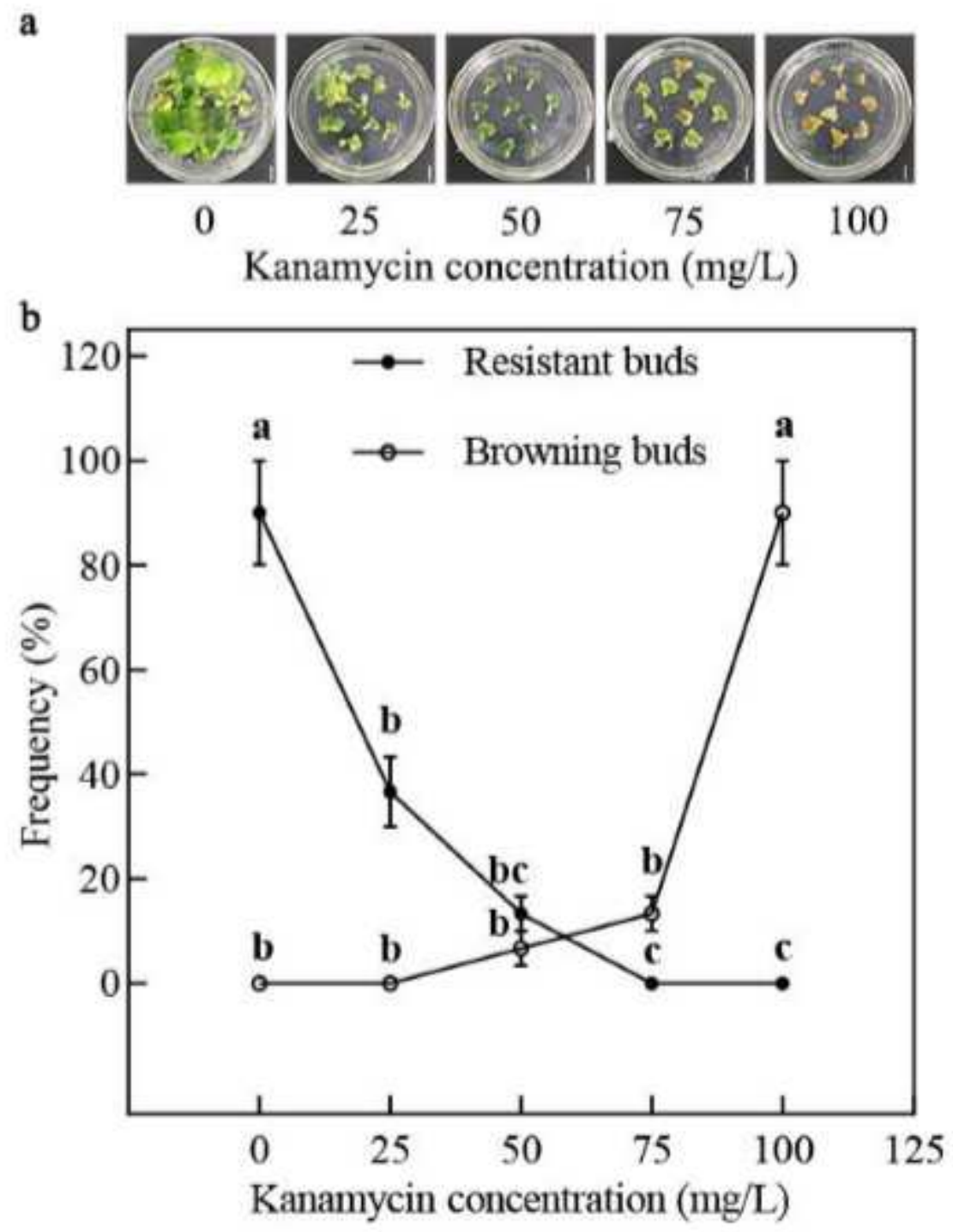

Figure 1

Browning and regeneration frequency of explants at different kanamycin concentrations. a, Growth and browning of explants at different kanamycin concentrations. Bar: $1 \mathrm{~cm}$. b, Analysis of variance of regeneration frequency and browning frequency. Values are the means of 3 replicates $\pm S E$, and 10 explants were repeated each time. Different lowercase letters show significant differences at $p<0.05$ by Tukey's test after analysis of variance. 
a

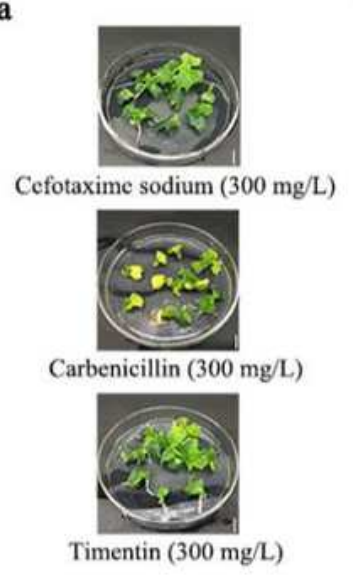

C Bacterial culture time

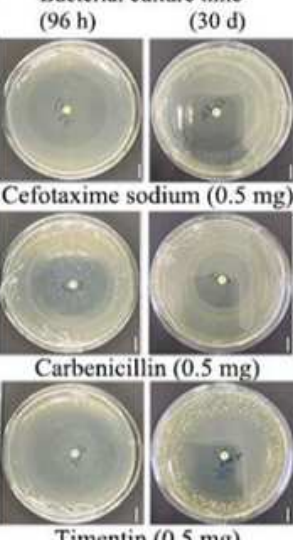

Timentin $(0.5 \mathrm{mg})$

e

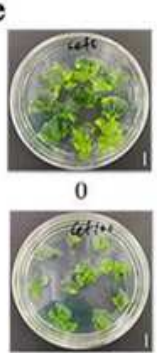

100

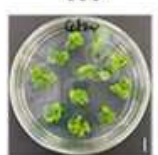

200

Cefotaxime sodium concentration $(\mathrm{mg} / \mathrm{L})$
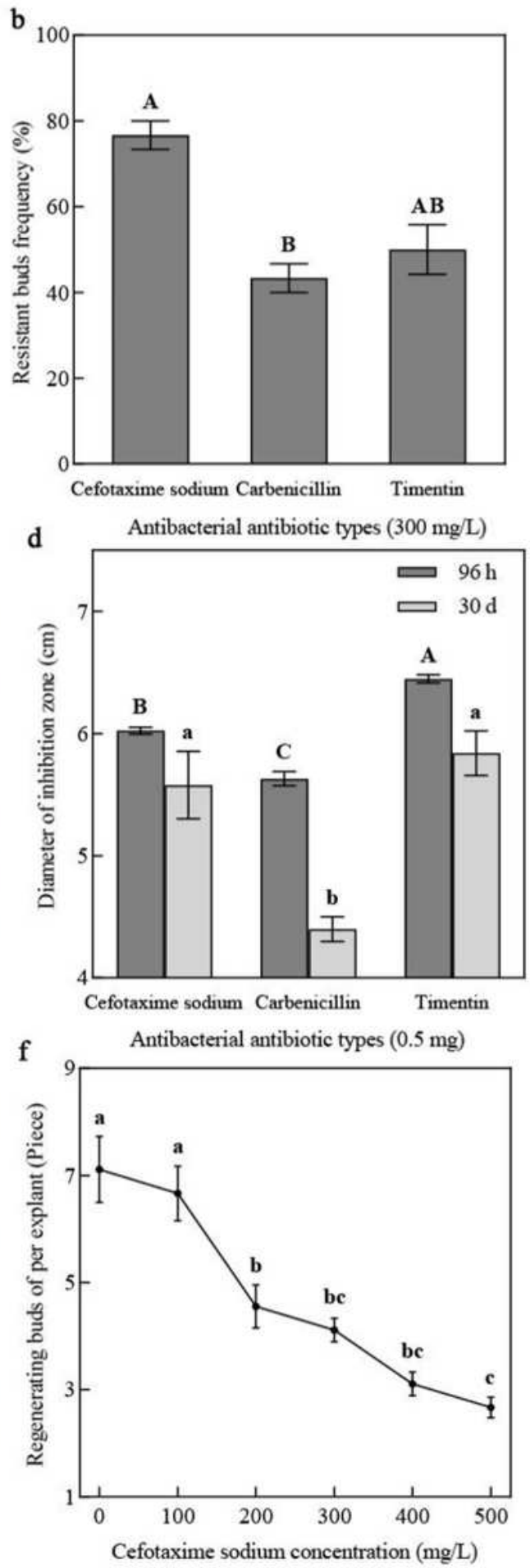

\section{Figure 2}

Effects of bacteriostatic antibiotics on Agrobacterium and explants. a, Growth of explants with different bacteriostatic antibiotics at $300 \mathrm{mg} / \mathrm{L}$. b. Analysis of variance of regeneration frequency with different bacteriostatic antibiotics at $300 \mathrm{mg} / \mathrm{L}$. c, Inhibitory effect of $0.5 \mathrm{mg}$ of different bacteriostatic antibiotics on Agrobacterium in $96 \mathrm{~h}$ and $30 \mathrm{~d}$. d, Analysis of variance of diameter of inhibition zone in $96 \mathrm{~h}$ and 30 d. e, Regeneration of explants at different concentrations of cefotaxime sodium. Bar: $1 \mathrm{~cm}$. f, Analysis of 
variance of regeneration buds per explant at different concentrations of cefotaxime sodium. Values are the means of 3 replicates $\pm S E$, and 10 explants were repeated each time. Different lowercase letters show significant differences at $p<0.05$, and different capital letters show high significance at $p<0.01$ by Tukey's test after analysis of variance.

a

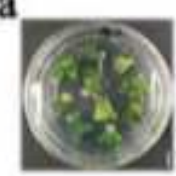

0

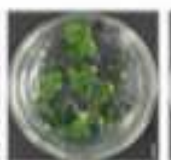

50

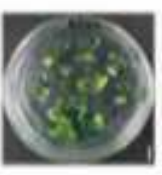

100

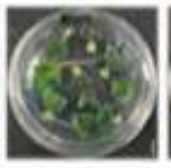

200

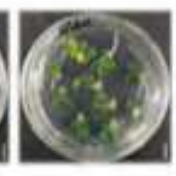

400

c

Acetosyringone concentration $(\mu \mathrm{M})$
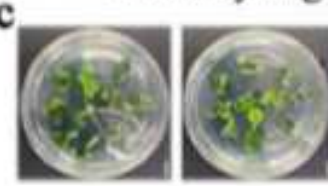

0

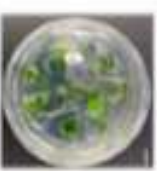

100

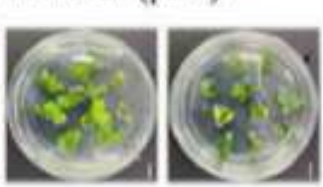

200

400

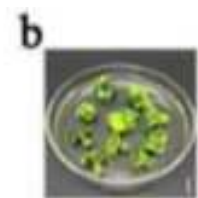

0

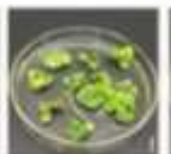

50

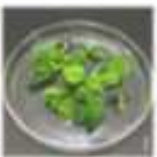

100

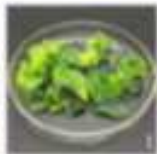

150

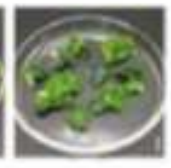

200

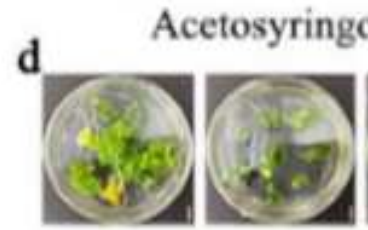

0
50

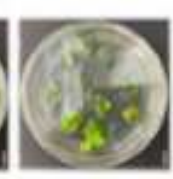

100

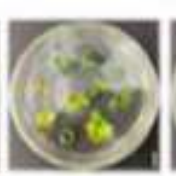

150 $(\mu \mathrm{M})$

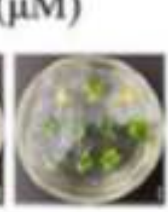

200
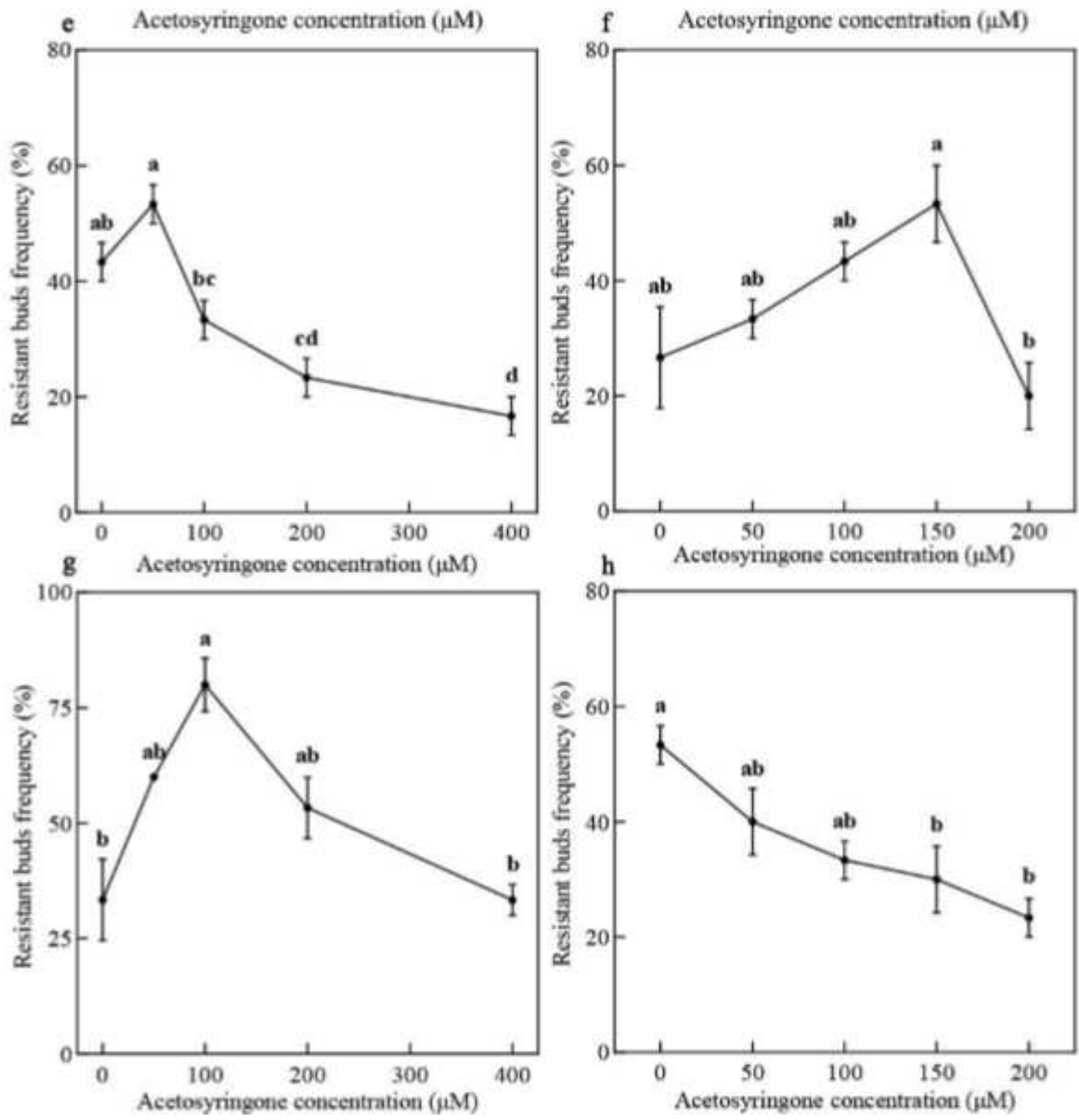

Figure 3 
Effect of acetosyringone on the regeneration of resistant buds. a, Growth of explants in the pre-cultivation stage with different concentrations of acetosyringone. $b$, Growth of explants in the infection stage with different concentrations of acetosyringone. $c$, Growth of explants in the co-cultivation stage with different concentrations of acetosyringone. $d$, Growth of explants in the selective culture stage with different concentrations of acetosyringone. Bar: $1 \mathrm{~cm}$. e, Analysis of variance of resistant bud frequency in the precultivation stage with different concentrations of acetosyringone. $f$, Analysis of variance of resistant bud frequency in the infection stage with different concentrations of acetosyringone. g, Analysis of variance of resistant bud frequency in the co-cultivation stage with different concentrations of acetosyringone. $h$, Analysis of variance of resistant bud frequency in the selective culture stage with different concentrations of acetosyringone. Values are the means of 3 replicates \pm SE, and 10 explants were repeated each time. Different lowercase letters show a significant difference at $p<0.05$ by Tukey's test after analysis of variance.

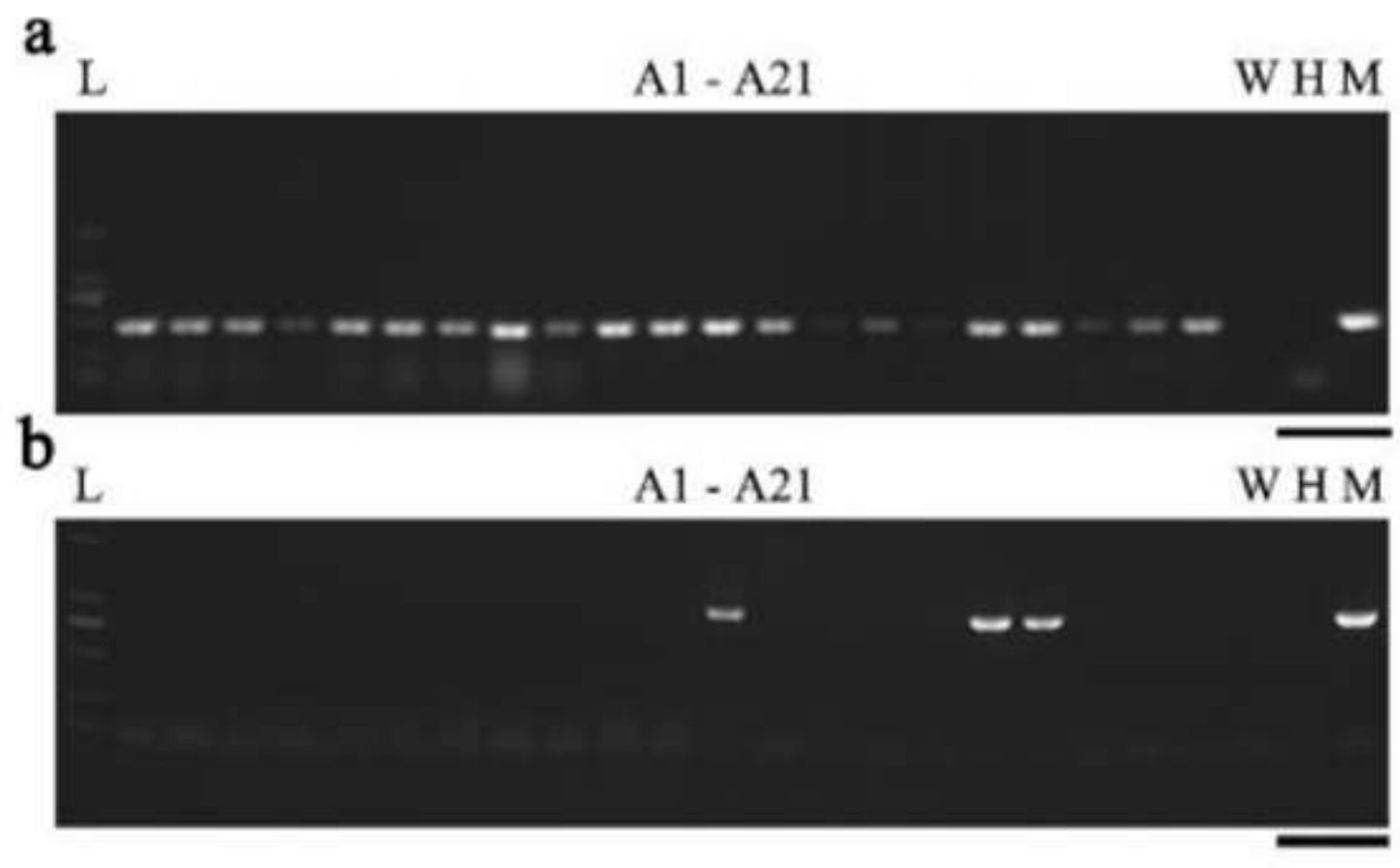

\section{Figure 4}

Gel electrophoresis of PCR products. a, Gel electrophoresis results for PCR products from npt II primers. b, Gel electrophoresis results for PCR products from HrcA primers. Lane $L$ is a line DNA marker of $2000 \mathrm{bp}$. Lanes A1-A21 are different independently regenerated plants. Lane $\mathrm{W}$ is a wild-type plant. Lane $\mathrm{H}$ is without template DNA (negative control). Lane M is genomic DNA of positive Agrobacterium (positive control). Bar: $1 \mathrm{~cm}$. 


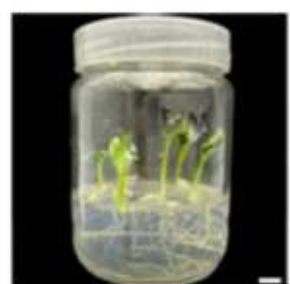

Step 1

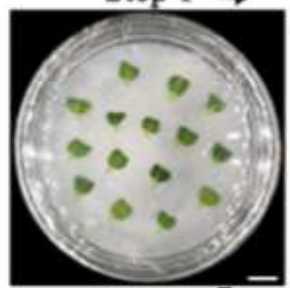

Step 3

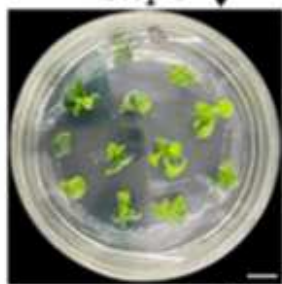

Step 45

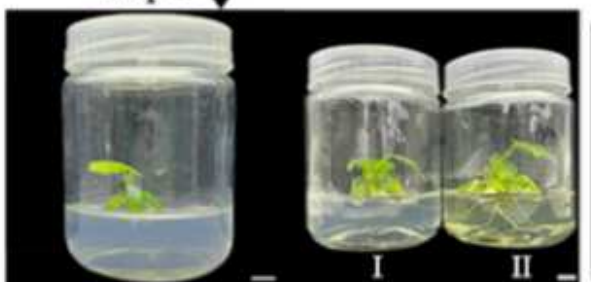

Cut off the resistant buds

ए了

Buds elongation culture

Medium: medium-IV containing $75 \mathrm{mg} / \mathrm{L}$ kanamycin and

$300 \mathrm{mg} / \mathrm{L}$ cefotaxime sodium

Condition: in the light at $28^{\circ} \mathrm{C}$ for $14 \mathrm{~d}$

\section{Step 2}

Preparation of Agrobacterium suspension (OD600-0.6-0.8)

Preparation of Agrobacterium inoculum $(O D 600=0.2-0.3)$

: medium-III containing $150 \mu \mathrm{M}$ acetosyringone, shaking at $28^{\circ} \mathrm{C}$ for $1 \mathrm{~h}$

Co-culture on filter paper wicks

medium-Il containing $100 \mu \mathrm{M}$ acetosyringone, $\mathrm{pH}=6.8$

Washing the explants with sterilized distilled water, $5 \mathrm{~min} \times 5$

Medium: medium-II containing $25 \mathrm{mg} / \mathrm{L}$ kanamycin and $300 \mathrm{mg} / \mathrm{L}$ cefotaxime sodium

Condition: in the light at $28^{\circ} \mathrm{C}$ for $14 \mathrm{~d}$

Medium: medium-II containing $50 \mathrm{mg} / \mathrm{L}$ kanamycin and $300 \mathrm{mg} / \mathrm{L}$ cefotaxime sodium

Condition: in the light at $28^{\circ} \mathrm{C}$ for $14 \mathrm{~d}$

$1 \mathrm{~min} ; 15 \% \mathrm{NaClO}, 15 \mathrm{~min}$;

Condition: in the dark at $28^{\circ} \mathrm{C}$

Condition in the dark at $28^{\circ} \mathrm{C}$ for $48 \mathrm{~h}$ acelosyringone, $\mathrm{pH}=6.8$

\section{Step 5}

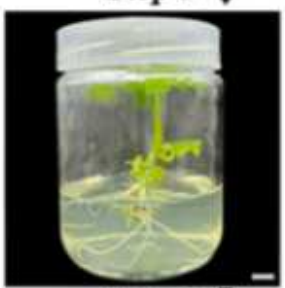

Step 6

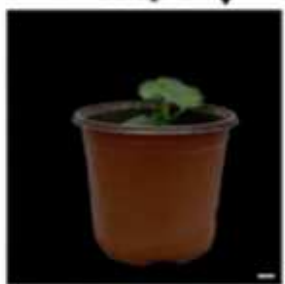

Step 7
Rooting culture

Medium: medium- $\mathrm{V}$ containing $100 \mathrm{mg} / \mathrm{L}$ kanamycin and $300 \mathrm{mg} / \mathrm{L}$ timentin

Condition: in the light at $28^{\circ} \mathrm{C}$ for $28 \mathrm{~d}$

Domestication on the matrix

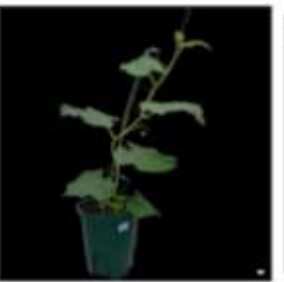

Transplantation to the soil

Step 8
Preparation of cotyledonary node explants

Medium: medium-II containing $50 \mu \mathrm{M}$ acetosyringone

Condition:

in the dark at $28^{\circ} \mathrm{C}$ for $24 \mathrm{~h}$

\section{Figure 5}

Steps in the transformation of cucumber 'Xintaimici' shoot organogenesis from cotyledonary node explants. Step 5-I, $300 \mathrm{mg} / \mathrm{L}$ timentin in culture medium as a bacteriostatic antibiotic. Step 5-II, $300 \mathrm{mg} / \mathrm{L}$ cefotaxime sodium in culture medium as a bacteriostatic antibiotic. Bar: $1 \mathrm{~cm}$. 